\title{
Digita - um Jogo Educativo de Apoio ao Processo de Alfabetização Infantil
}

\author{
Ding Yih An ${ }^{1}$, Cesar Dick da Silva ${ }^{1}$, Danton Moura G. Ribeiro ${ }^{1}$, Perla Batista R. da \\ Rocha $^{1}$, Caio Maltinti ${ }^{1}$, Vanessa Battestin Nunes ${ }^{1}$, Rutinelli Fávero ${ }^{1}$ \\ ${ }^{1}$ Instituto Federal do Espírito Santo (Ifes) \\ Rodovia ES-010 - Km 6,5 - Manguinhos 29173-087 - Serra - ES - Brasil \\ \{sidnha, cesardickdasilva, dantonmoura, perlaleo, ccmcaio\}@gmail.com, \\ \{vanessa, rutinelli\}@ifes.edu.br
}

\begin{abstract}
This article describes the educational game Digita, developed in order to support children's literacy utilizing the benefits that games bring to the process of learning and teaching, and literacy methods that involve more than the mechanical repetition of exercises. It is a free tool that can be used in schools with pre-school and elementary. The game was well evaluated by an expert in the education area, in the pedagogical and usability requirements, and she also pointed aspects to be improved in future work.
\end{abstract}

Resumo. Esse artigo descreve o jogo educativo Digita, desenvolvido com o intuito de apoiar a alfabetização de crianças utilizando os benefícios que os jogos trazem para o processo de aprendizado e ensino, além de métodos de alfabetização que envolvam mais do que a repetição mecânica de exercícios. Trata-se de uma ferramenta livre, que poderá ser utilizada em escolas da educação básica (educação infantil e ensino fundamental). O jogo foi bem avaliado por uma especialista da área educacional, quanto aos requisitos pedagógicos e de usabilidade, que também apontou aspectos a serem melhorados em trabalhos futuros.

\section{Introdução}

A alfabetização de crianças é um tema complexo e, por isso mesmo, amplamente abordado por teóricos da área. Numa visão geracional dos aspectos educativos, vinda após a geração Y, nas quais fazem parte as pessoas nascidas entre 1981 a 2000, a geração $\mathrm{Z}$ é composta por pessoas que muitas vezes aprendem a se conectar antes de aprender a ler, que fazem diversas tarefas ao mesmo tempo e são conhecidos como os "nativos da Internet". Assim, o ensino para a geração Z está se transformando, pois aulas expositivas tem se tornado insuficientes para atingir o sucesso do aprendizado, sendo indicados trabalhos que favoreçam a interação do aluno, principalmente pela dinamicidade que caracteriza essa geração [Siqueira 2012].

As novas tecnologias existentes na sociedade são fatores positivos para o processo de ensino e aprendizagem, evoluindo a forma com que a didática pode ser trabalhada [Andrade 2012]. Essa situação favoreceu o surgimento da informática educativa nas escolas, em que diversos jogos digitais foram construídos para colaborar com o processo de ensino e aprendizagem [Godinho 2004]. Podemos citar, como trabalhos correlatos, os jogos educativos para alfabetização: PRO-EDU [Ribeiro 2013], Alfa-móvel [Marinho 2013] e Veritek [Godinho 2013]. 
Porém, em pesquisas realizadas no final da década de 90 evidenciou-se que muitos dos softwares existentes não enfatizavam a importância de um contexto para a alfabetização, buscando apenas exercitar a escrita e leitura da palavra, os "... famosos exercícios de prontidão que se limitam ao adestramento da criança..." [Stemmer, 2001, p.3]. Em uma análise mais geral sobre os principais softwares da atualidade, percebe-se que também são carentes de atividades que envolvam mais do que o treino de habilidades. Faltam desafios à criança.

Neste contexto, torna-se pertinente o desenvolvimento de um software educativo que envolva o processo de alfabetização, mas que, também, compreenda um contexto familiar à criança e que a desafie. É nesses termos que se desenvolveu o jogo digital educativo - Digita, foco deste trabalho.

O Digita trata-se de um jogo interativo onde a criança é desafiada a apontar soluções para uma situação, que é apresentada por imagens e diálogos de personagens. É apresentada à criança uma situação ou problema e ela deve selecionar uma solução entre as muitas possíveis e descrever essa solução, digitando a palavra ou ordenando suas sílabas, de acordo com o nível de alfabetização que possui. Para cada problema são possíveis diversas soluções e cada uma delas cria alterações no cenário, mostrando uma animação diferente. Um exemplo de problema é uma garota com um gato preso em uma árvore, onde a criança pode apontar, como resposta, palavras como escada, asas, etc.

Observa-se, então, que este trabalho propõe um jogo que não trata apenas da memorização de palavras ou de exercícios mecânicos, mas envolve a criança em seu mundo (pois traz cenários familiares ao mundo infantil) e, a partir desse cenário, as palavras a serem aprendidas. "Ler a palavra e aprender como escrever a palavra, de modo que alguém possa lê-la depois, são precedidos do aprender como "escrever" o mundo, isto é, ter a experiência de mudar o mundo e de estar em contato com o mundo [Freire; Macedo, 1990, p.31]". Pensando assim, tal como Brandão, diz-se que:

\footnotetext{
Ora, leitor, há uma ideia que será dita e repetida aqui algumas vezes, $\mathrm{O}$ método aponta regras de fazer, mas em coisa alguma ele deve impor formas únicas, formas sobre como fazer. De uma situação para outra, de um tempo para outro, sempre é possível criar sobre o método, inovar instrumentos e procedimentos de trabalho. [Brandão, 2008, p.13]
}

Nesse sentindo, buscou-se compreensão e inspiração no pensamento de Paulo Freire, no que se refere à alfabetização. Mesmo que no jogo haja tarefas que envolvam ordenação ou digitação de sílabas, as palavras tem significado dentro de um contexto.

Segundo Paulo Freire (1989), não é interessante um processo de alfabetização em que haja apenas uma memorização repetitiva dos "ba-be-bi-bo-bu", não podendo minimizar a alfabetização ao ensino puro da palavra, das sílabas e das letras. Outra questão importante é a escolha das palavras que farão parte do jogo e, com isso, do processo de alfabetização. Importante escolher com base não apenas na riqueza fonêmica da palavra ou nas dificuldades fonéticas, mas tão importante quanto esses itens é o sentido que essa palavra traz em relação às crianças [Brandão 2008].

\section{A alfabetização infantil}

Cada criança possui distintas interações com o código escrito e, de acordo com seu uso social, ela constrói hipóteses que se unem com suas próprias experiências, enriquecem e significam o processo. Por esse motivo, é importante ela entre em contato com o uso 
social da leitura e da escrita, reconhecendo a função social da linguagem [Lorenzet e Girotto 2010].

O processo da alfabetização é influenciado também pelas experiências prévias de cada alfabetizando, assim, quando ele chega a uma situação em que precise ler ou escrever, ele busca estratégias para tentar identificar, interpretar o que está no texto decodificado pelas letras. Mediante um texto, as crianças elaboram hipóteses e tem critérios investigativos para descobrir e desvendar as informações escritas importantes tais como: jornais, livros, revistas, anúncios escritos nas propagandas de televisão, sites diversos e nos jogos. Elas usam informações prévias tais como: tipo e tamanho de letra, sua cor, indícios das gravuras que o texto traz e, assim, montam uma representação da mensagem. Esse processo de investigação traz uma reflexão mental elaborada desde as primeiras noções que podem construir em torno da leitura. Esse conjunto é o que constrói o contexto do universo de letramento, em uma mútua ligação com a alfabetização [Lorenzet e Girotto 2010].

Dentre os métodos mais tradicionais de alfabetização, há aqueles de marcha sintética - cujo estudo tem origem na "parte" e depois no "todo" - são: soletração, que parte do nome das letras, também chamado de alfabético; fônico, que parte dos sons correspondentes às letras; silabação, partindo das sílabas, com emissão de sons. Esses métodos iniciam o ensino da leitura com um grau de dificuldade e esse vai aumentando com o decorrer do tempo, em que as partes vão sendo agrupadas para a formação de uma palavra, frase ou pequeno texto (ou seja, da "parte" para o "todo"). Com relação à escrita, o ensino ocorre por meio de cópias, ditados e formação de frases, restringindose à caligrafia e ortografia [Mortatti 2006]. Já no método analítico, o aprendizado inicia pelo "todo" e depois procede-se a análise de suas partes constituintes. O "todo" pode ser a palavra, a sentença ou a historieta, que é um conjunto de frases relacionadas entre si por meio de nexos lógicos [Mortatti 2006].

Há questões que devem ser abordadas sobre os métodos citados, principalmente o sintético, como a não priorização da interação do que está sendo ensinado com o contexto do letrando. A simples decodificação não permite à criança o conhecimento necessário para estar realmente alfabetizada, quando se entende que ela terá a apreensão do que lê ou escreve, relacionando com seu próprio cotidiano [Mortatti 2006]. Ainda que haja essas questões, esses métodos tem sua importância na alfabetização, pois é necessário ao alfabetizando memorizar a grafia e exercitá-la. Poderia ser interessante para processo de o ensino-aprendizagem da leitura e escrita atividades que envolvam os métodos tradicionais, mas que o texto e/a palavra estejam presentes em um contexto que faça sentido para a criança, como defende a teoria de Freire.

\section{Jogos como ferramenta de apoio ao processo de ensino-aprendizagem}

O jogo exerce um papel importante para a crianças, entre outros de motivador, fazendo com que ela faça esforço para atingir o objetivo estipulado e, como consequência, pode ser parte do processo de aprendizagem [Godinho 2004].

Segundo Passerino, "Os jogos educativos são criados com a finalidade dupla de entreter e possibilitar a aquisição de conhecimento" [1998 apud Godinho 2004]. O brincar tem uma função importante na aprendizagem e na socialização, pois dessa forma a criança contrai motivação e aptidões que são importantes para sua participação no meio social [Nobre et al. 2011]. 
Há críticos que argumentam que atividades produzidas nos jogos são irrelevantes ou inconsequentes, que trazem vícios, que tornam as crianças antissociais [Nobre et al. 2011]. Porém, o jogo, quando possui determinadas características, é um meio de estimular na criança a vontade de aprender, com ludicidade.

Os softwares educacionais, para estarem apropriados para o seu uso no processo de aprendizagem, devem seguir determinados critérios e serem avaliados quanto aos mesmos. Para autores com enfoque mais técnico, ligados à Ciência da Computação, como Oliveira e outros [2001 apud Albernaz 2008], as etapas que devem ser consideradas para o desenvolvimento do software educativo podem ser assim enumeradas: seleção do conteúdo; verificação dos conhecimentos prévios que se precisa; definição dos conceitos sobre a estrutura do conteúdo; elaboração do diagrama de fluxo; construção das telas e implementação das mesmas (diagrama de fluxo, documentação, layout e associação entre as telas); elaboração da documentação do software; uso, verificação e manutenção do software.

Além dessas, os jogos educativos também devem considerar os critérios que são baseados em teorias construtivistas e interacionistas. Segundo Campos, F. \& Campos, G. H. (1997, apud NOBRE, 2011), aprofundado posteriormente pelo mesmo autor (1998, apud ALBERNAZ, 2008) os desenvolvedores deveriam: sugerir ambientes que possibilitem o aprendizado sob múltiplas perspectivas; sugerir contextos compatíveis com o conhecimento além da sala de aula; possibilitar a interpretação significativa e reflexiva; estimular o pensamento crítico; fomentar a comunicação, de modo que haja troca de ideias e análise de diferentes alternativas e prover apoio ao aluno, ao contexto da aprendizagem e ao processo.

O software educativo precisa apresentar como um dos requisitos principais a usabilidade, além de produzir algum conhecimento. Deve seguir ainda outros critérios de características de qualidade, compatibilidade e tolerância a erros. Também devem apresentar um feedback ao usuário que facilite o aprendizado, como pistas da resposta correta, levando a uma reflexão sobre seu erro, para que não seja apenas um jogo de tentativa e erro, o que não traria contribuição para o processo de aprendizado da criança [Albernaz 2008]. Sendo assim, além dos requisitos de qualidade comuns a outros programas computacionais, os jogos educativos precisam ter atributos pedagógicos, voltados para o aprendizado efetivo do seu público-alvo, no caso as crianças em processo de alfabetização.

\section{Metodologia e o processo de construção do jogo}

Para o processo de construção do Digita foi realizada uma revisão de literatura sobre os principais temas abordados: alfabetização e uso de jogos computacionais na educação. Com base nesses assuntos, definiram-se as diretrizes principais para o projeto.

Para desenvolver o software proposto neste trabalho, foi utilizado o modelo de ciclo de vida em espiral, proposto por Boehm, que é um dos modelos evolutivos mais difundidos, permitindo o desenvolvimento do sistema em ciclos, sendo que nem sempre nos primeiros ciclos todas as atividades são realizadas. Os ciclos vão sendo passados e chegando progressivamente a versões operacionais do software [Pressman 1995]. Além disso, foram realizadas algumas atividades para construção de softwares educativos que constam em Albernaz (2008). 
Na fase de Análise e Especificação de Requisitos, priorizou-se o levantamento, o entendimento e a especificação dos requisitos que o Digita deve ser capaz de satisfazer. Para tal, foram construídos diagramas em linguagem UML, utilizando a ferramenta Astha Community. Foram feitos os diagramas de caso de uso, de classes e de estado. Abaixo, o diagrama de caso de uso do sistema Digita, explicitando suas principais funcionalidades:

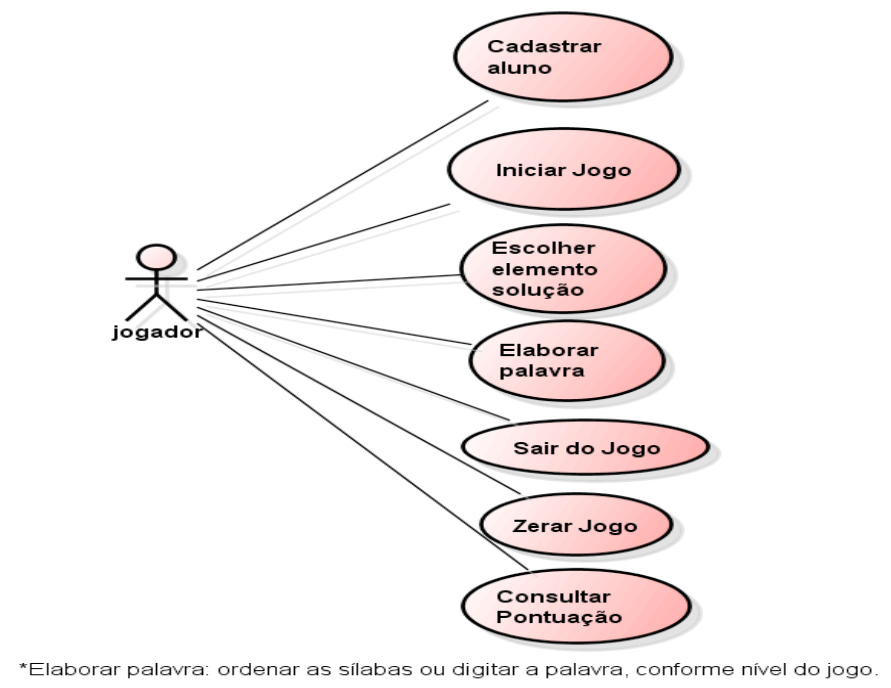

Figura 1. Diagrama de Casos de Uso do Digita

$\mathrm{Na}$ fase de Projeto foram incorporados os requisitos tecnológicos aos requisitos efetivos do sistema [Falbo 2013]. Para modelar a persistência, foi feito o diagrama relacional. $\mathrm{O}$ banco de dados utilizado foi o Postgre. $\mathrm{O}$ jogo foi implementado utilizando a linguagem C\#, na plataforma Dot Net.

Por fim, o jogo foi analisado por uma especialista da área educativa com o objetivo de avaliar o alcance dos objetivos esperados e de apontar suas considerações e sugestões para melhoria do mesmo.

\section{O jogo Digita}

O Digita foi construído de forma a ser atrativo às crianças e envolvendo cenários com objetos comuns ao ambiente infantil. Os cenários, objetos e personagens do jogo foram todos elaborados por um dos autores do presente artigo.

Na Figura 2, a primeira tela apresentada é a do login e a segunda é a tela de menu, em que são feitas a escolha das fases (cenários) e do nível (fácil ou avançado).

No login, a criança deve se cadastrar, sendo aconselhado o apoio de um adulto para essa parte inicial. O login é importante como um meio de a criança se identificar e assim ser possível associar a ela uma quantidade de pontos que será adquirida com o decorrer do jogo. A pontuação é um estímulo para que a criança tente conseguir mais soluções em cada fase. Além disso, se a criança for do sexo feminino o personagem do jogo será uma menina e se for do sexo masculino será um menino.

No menu, o jogador pode verificar as opções do jogo, facilitando a interação e a escolha dos cenários que já foram conquistados, mas ainda não concluídos, ou seja, aqueles em que ainda há alguma solução não descoberta (ilustrado pelas estrelas pretas). 

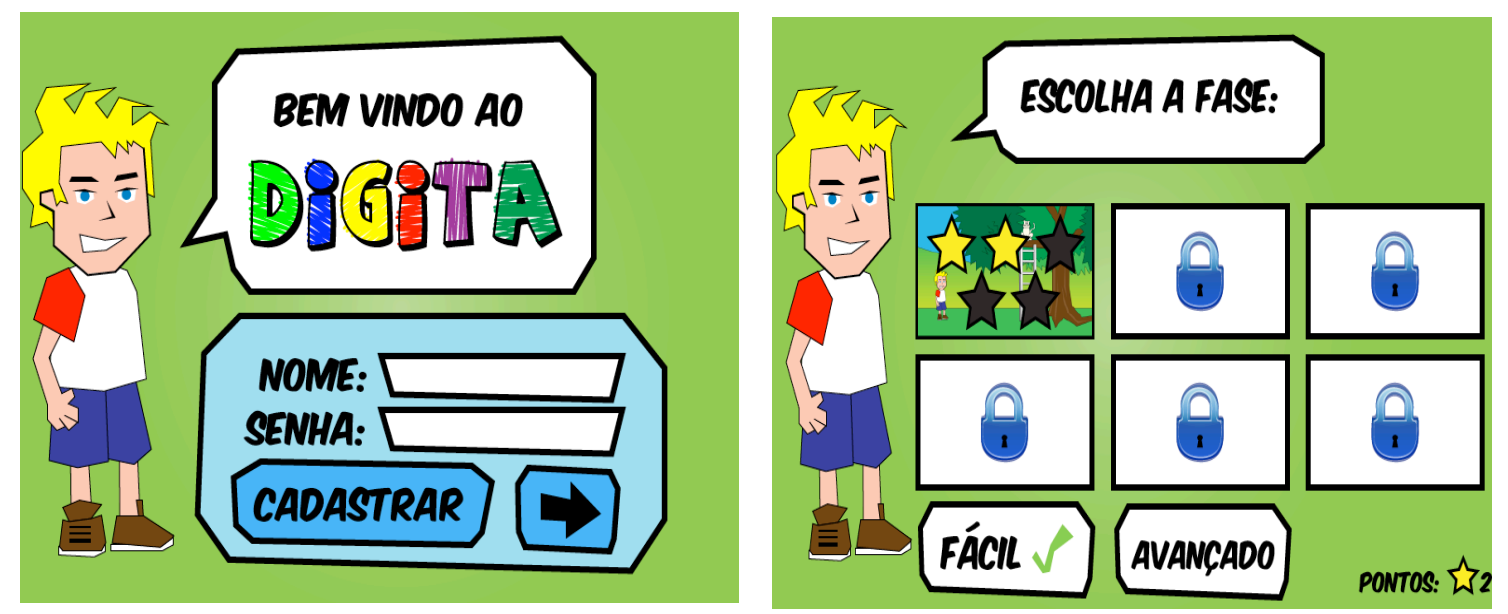

Figura 2. Tela de Login e Tela de Menu

A primeira tela da Figura 3 mostra o primeiro cenário do jogo, em que a criança está diante de um problema a ser resolvido (no caso, um gato em uma árvore) e é apresentada uma mochila, de forma destacada, que é o caminho para solução do mesmo.

Ao clicar na mochila, será exibida a segunda tela da Figura 3, com os objetos para que a criança escolha algum como solução para o problema.
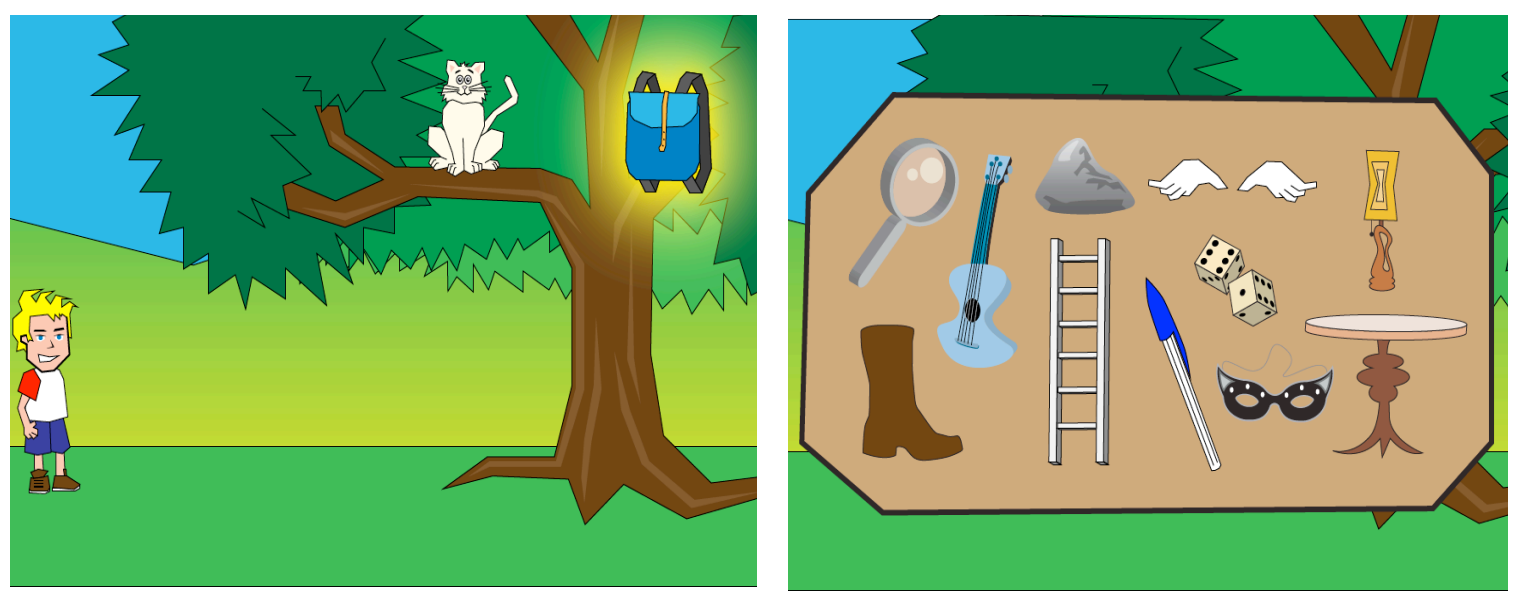

Figura 3. Tela com o cenário inicial e tela com a mochila aberta com os objetos para escolha

Esse primeiro cenário apresenta o seguinte problema a ser resolvido: descobrir um objeto que sirva para resgatar o gato da árvore. As falas dos personagens com instruções úteis ao jogo têm a opção de serem somente escritas ou, no nível fácil, de ter um áudio correspondente. Isso faz com que haja uma conformidade com o grau de alfabetização que a criança possui.

$\mathrm{Na}$ tela da mochila, cabe à criança pensar e refletir quais dos objetos disponibilizados serão úteis para resolver o problema. Existem cinco soluções possíveis e ela precisa completar no mínimo três para passar de fase. Mesmo que a criança escolha um objeto impróprio para a situação, como uma caneta, por exemplo, para o cenário do gatinho na árvore, o Digita permitirá que ela prossiga com a digitação ou ordenação da palavra e somente após tê-la completado com êxito exibirá uma mensagem explicando que, embora tenha construído a palavra com sucesso, aquele 
objeto não pode resolver o problema. O objetivo é estimular a criança a pensar melhor na escolha do objeto certo, o que é importante por exigir da criança a interpretação do cenário, o pensar sobre a função de cada objeto e como o mesmo pode ser útil ou não naquele contexto. A criança não vai jogar o Digita apenas para codificar ou decodificar letras. Há um desafio maior.

A Figura 4 apresenta, à esquerda, a tela em que a criança está ordenando as sílabas para formar a palavra correspondente ao objeto escolhido. Em níveis mais avançados, ao invés de palavras a serem ordenadas, a criança teria que digitar a palavra.

A tela à direita, da Figura 4, mostra um momento da animação que é feita quando o jogador escolheu o objeto apropriado e ordenou a palavra corretamente. A animação é apresentada de forma a demonstrar o "final feliz" e parabenizar o jogador pelo seu sucesso (no caso, por ter resgatado o gato da árvore). Serve como estímulo e uma forma de reconhecimento pelo trabalho realizado (o que fica representado pela estrela amarela, ou seja, um objetivo foi conquistado).
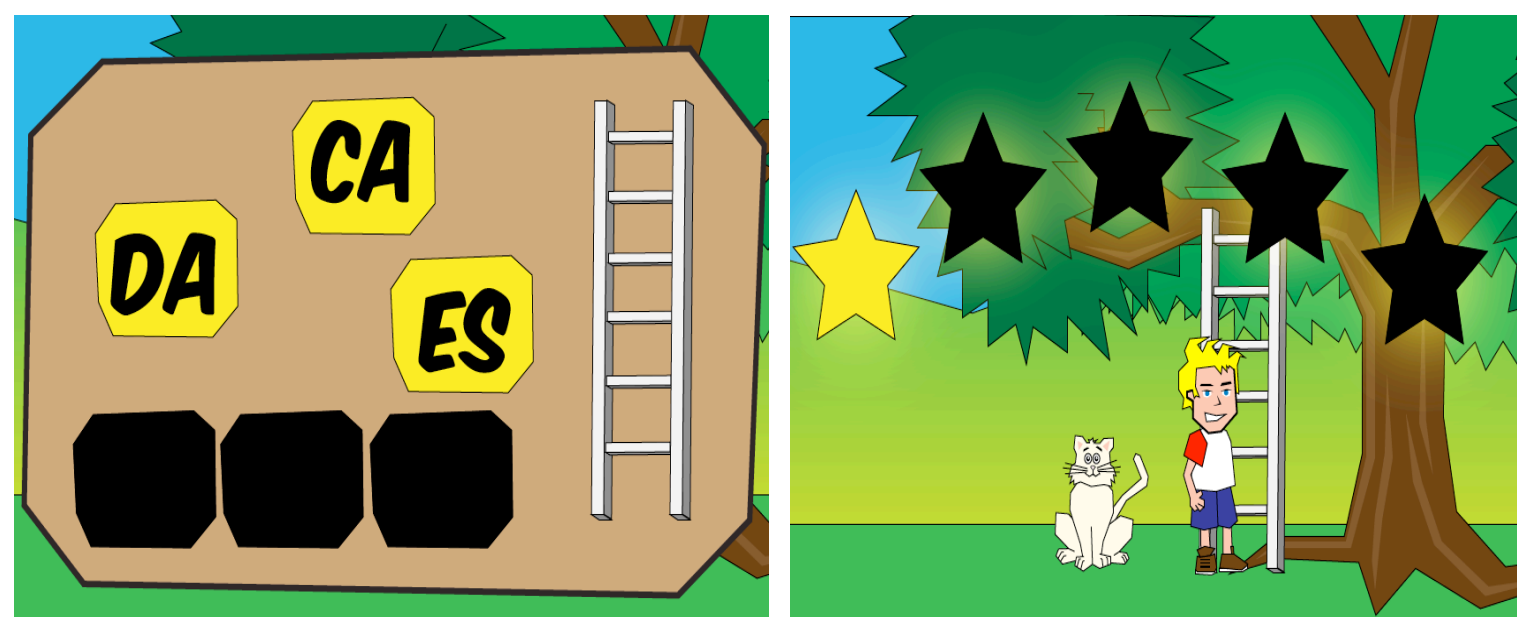

Figura 4. Tela em que a criança ordena as sílabas do objeto escolhido e tela com um momento da animação que é apresentada ao final da solução

Os cenários do jogo, em sua maioria, contêm situações cotidianas e problemas simples de se resolver. Como o público alvo são crianças em fase de alfabetização, buscou-se permitir que a criança use sua imaginação para resolver o problema. Afinal, num mundo real, gatos não tem asas, mas num mundo dentro do imaginário infantil, o gato pode usar as asas para voar. O Digita pretendeu fazer uso dessa visão da criança, explorando a ludicidade e a criatividades próprias da fase infantil.

O objetivo final do jogo é que o usuário conclua todas as fases, passando pelos por diversos cenários com situações distintas, em cada uma delas exercitando o raciocínio, a imaginação e a grafia das palavras.

Espera-se que o Digita auxilie o processo de alfabetização com um aprendizado divertido, estimulando o pensar da criança e o seu entendimento sobre a codificação de palavras, que é exercitada nas partes de ordenação ou digitação das soluções.

\section{Avaliação por um especialista}

Para uma melhor análise sobre o jogo Digita, convidamos uma especialista da área de educação para avaliá-lo. Para isso, foi desenvolvido um questionário baseado nos 
trabalhos [Albernaz 2008] e [Nobre et al. 2011], destacando requisitos de usabilidade e requisitos pedagógicos,tendo como possíveis respostas: atende plenamente, atende parcialmente, não atende e não se aplica. Além disso, foi deixado um espaço para a avaliadora fazer suas considerações e sugestões para melhorias do jogo, como mostra a Tabela 1.

Tabela 1. Avaliação do especialista

\begin{tabular}{|c|c|c|c|c|}
\hline REQUISITOS & Atende & $\begin{array}{c}\text { Atende } \\
\text { Parcialmente }\end{array}$ & Não Atende & $\begin{array}{l}\text { Não se } \\
\text { aplica }\end{array}$ \\
\hline \multicolumn{5}{|l|}{ Requisitos de Usabilidade } \\
\hline $\begin{array}{l}\text { 1. A linguagem e é adequada ao público alvo definido e } \\
\text { ao nível de ensino a que se refere. }\end{array}$ & $x$ & & & \\
\hline $\begin{array}{l}\text { 2. O jogo é atrativo, envolvendo e cativando o aluno em } \\
\text { sua utilização. O espaço é explorado e são usadas } \\
\text { múltiplas mídias (imagens, animações, vídeos, } \\
\text { música etc) }\end{array}$ & & $x$ & & \\
\hline $\begin{array}{l}\text { 3. O tema é apresentado de forma lúdica e explora uma } \\
\text { metáfora esclarecedora para o aluno. }\end{array}$ & & $x$ & & \\
\hline $\begin{array}{l}\text { 4. O jogo permite e incentiva a crescente autonomia e o } \\
\text { envolvimento. }\end{array}$ & & $x$ & & \\
\hline \multirow{2}{*}{$\begin{array}{l}\text { 5. O aluno consegue interagir com o jogo facilmente. } \\
\text { Existe interação com outros usuários. As interações } \\
\text { são seguras e promovem os objetivos do jogo. }\end{array}$} & $x$ & & & \\
\hline & & & & $x$ \\
\hline $\begin{array}{l}\text { 6. Promove a criatividade (podem existem vários } \\
\text { caminhos/respostas/soluções). }\end{array}$ & $x$ & & & \\
\hline $\begin{array}{l}\text { 7. O tempo de cada ação é adequado. Existe a } \\
\text { possibilidade de repetição. As etapas não são } \\
\text { exaustivas. }\end{array}$ & $x$ & & & \\
\hline $\begin{array}{l}\text { 8. As regras do jogo são coerentes e elas estão de } \\
\text { acordo com o mundo imaginário proposto pelo jogo. }\end{array}$ & $x$ & & & \\
\hline $\begin{array}{l}\text { 9. O nível de concentração exigido está de acordo com } \\
\text { o público do jogo. }\end{array}$ & $x$ & & & \\
\hline \multicolumn{5}{|l|}{ Requisitos Pedagógicos } \\
\hline $\begin{array}{l}\text { 10. O conteúdo é coerente e contextualizado com a } \\
\text { área e o nível de ensino propostos. }\end{array}$ & $x$ & & & \\
\hline $\begin{array}{l}\text { 11. O grau de dificuldade do programa é variável, } \\
\text { podendo ser definido pelo aluno ou passando de } \\
\text { níveis de dificuldade menor para maiores, de } \\
\text { acordo com os avanços obtidos. }\end{array}$ & $x$ & & & \\
\hline $\begin{array}{l}\text { 12. Aborda os conteúdos de forma a facilitar o } \\
\text { aprendizado. }\end{array}$ & & $x$ & & \\
\hline $\begin{array}{l}\text { 13. Oferece feedbacks construtivos, permitindo ao } \\
\text { aluno identificar claramente quando acertou e } \\
\text { repensar suas ideias e estratégias quando não } \\
\text { forem bem sucedidas Possui possibilidade de e } \\
\text { autocorreção. }\end{array}$ & & $x$ & & \\
\hline $\begin{array}{l}\text { 14. O número de pontos obtidos é computado e é dado } \\
\text { algum incentivo ou premiação ao se atingir certos } \\
\text { marcos, a fim de motivar o aluno. }\end{array}$ & $x$ & & & \\
\hline $\begin{array}{l}\text { 15. Faz referência ao universo cotidiano dos alunos, } \\
\text { em uma perspectiva de formação e de cidadania. }\end{array}$ & & $x$ & & \\
\hline
\end{tabular}

\section{Considerações / Sugestões de Melhorias}

O objetivo (colaborar com a alfabetização) é complexo;

7. Não há tempo definido para as ações. Talvez no nível médio definir tempo amplie as possibilidades de interação com o jogo e o grau de dificuldade;

13. e 15. A sugestão é de fossem possíveis feedbacks específicos de cada erro. Por exemplo, no caso da criança escolher uma pedra para tirar o gatinho da árvore, o feedback poderia objetivar uma mudança de visão e a construção de uma diferente forma de lidar com a agressividade a partir do respeito pelas formas de vida possibilitando uma educação cidadã. 
A avaliadora é professora e já atuou como pedagoga, tendo experiência no ensino infantil, fundamental e superior. $O$ resultado de sua avaliação consta na Tabela 1.

Pode-se verificar que o jogo teve uma boa avaliação em todos os 15 itens, sendo que em nove a avaliadora considerou que ele atende plenamente e em seis que atende parcialmente. Porém, apesar de nenhum item ter sido marcado como "Não atende", ainda assim os itens marcados como "Atende parcialmente" precisam de atenção para futuras melhorias. Uma sugestão interessante citada pela avaliadora foi a de fornecer feedbacks específicos de cada erro:

Por exemplo, no caso da criança escolher uma pedra para tirar o gatinho da árvore, o feedback poderia objetivar uma mudança de visão e a construção de uma diferente forma de lidar com a agressividade a partir do respeito pelas formas de vida possibilitando uma educação cidadã. (Avaliadora)

\section{Conclusões}

Este artigo teve como objetivo abordar como um jogo educativo, voltado para a alfabetização de crianças, pode trabalhar de forma interativa e atrativa com exercícios de codificação de palavras, mas sem se restringir a isso. Afinal, buscou-se com o Digita estimular a imaginação e o raciocínio para solução de problemas dentro de contextos familiares à criança.

Em determinadas situações do jogo, em que a criança ordena inadequadamente uma palavra, há um feedback explicando que ela precisa tentar de novo, pois a palavra não corresponde ao objeto. Da mesma forma, quando elabora a palavra corretamente, mas o objeto não é útil para a solução, há uma mensagem, parabenizando-a pela correta formação da palavra, mas explicando que o elemento escolhido não resolve o problema.

Apenas algumas partes do jogo foram implementadas. Assim, em trabalhos futuros, deverão ser acrescentadas outras funcionalidades. Além disso, poderão ser inseridos outros feedbacks, por exemplo, quando uma criança digitar uma palavra que foneticamente estaria correta, mas na sua escrita não, como "casa" ser digitado "caza", haveria uma mensagem, dizendo algo parecido com "você está perto da solução" e destacar a letra que está errada, para que a criança perceba o que precisa acertar, já que, nesse caso, o erro não é desprovido de lógica, necessitando o exercício da ortografia.

Outro trabalho futuro seria disponibilizar relatórios que permitam uma melhor análise dos educadores sobre seus alunos, especialmente sobre onde se concentram os erros e dificuldades, ou para montar competições entre eles, estimulando o aprendizado.

Por fim, seria muito importante utilizar o jogo com grupos de crianças, visando identificar as dificuldades de uso, os aprendizados obtidos, se ele se mostraram motivados em sua utilização entre outros. E, além disso, estabelecer procedimentos metodológicos para coleta e análise dos dados, visando posteriores melhorias.

\section{Referências}

Albernaz, J. M. (2008) "Jogo Computacional como Desencadeador da Aprendizagem de Matemática nas Séries Iniciais do ensino fundamental: sua avaliação por professores e alunos." Disponível em < http://www.ppge.ufes.br/dissertacoes/2010/ADRIANA\%20LANA.pdf>. Acesso em 09/06/2013. 
Andrade, E. D et al (2012) "O pedagogo e as novas tecnologias". In: Workshop de Informática na Escola (WIE) (2012). Disponível em <http://www.brie.org/pub/index.php/wie/article/view/2106/1872>. Acesso em 05/08/2013.

Brandão, C. R. (2008) "O que é método Paulo Freire" 29a . São Paulo: Brasiliense.

Falbo, R. A. (2012) "Engenharia de Software, Notas de Aula."Disponível em $<$ http://www.inf.ufes.br/ falbo/node/14>. Acesso em 09/06/2013.

Freire, P.. (1989) "A importância do ato de ler em três artigos que se completam." São Paulo: Autores Associados: Cortez..Freire, P..e Macedo, D. (1990) "Alfabetização: leitura do mundo leitura da palavra". Rio de Janeiro: Paz e Terra.

Godinho, M. B.(2004) "O Papel do Jogo Computacional Veritek na Alfabetização." Disponível em <https://www.repositorioceme.ufrgs.br/bitstream/handle/10183/37199/000486997.pd f?sequence=1> Acesso em 09/06/2013.

Lorenzet, D. e Girotto, J. C. (2010). "A Alfabetização e Letramento na Prática Pedagógica." Disponível em < http://www.reitoria.uri.br/ vivencias/Numero_010/artigos/artigos_vivencias_10/p1.h tm\#_ftn6>. Acesso em 08/06/2013.

Marinho, Carlos S. R, et al. "O Celular e a Alfabetização: Uma Ferramenta de Apoio". Anais do XXII SBIE. Aracaju, 2011. Disponível em <http://brie.org/pub/index.php/sbie/article/view/1858>. Acesso em 09/06/2013.

Mortatti, M. R. L. (2006) "História dos Métodos de Alfabetização no Brasil." Disponível em < http://www.sema.edu.br/editor/fama/livros/educacao/HISTORIA\%20DA\%20EDUC A\%C3\%87\%C3\%83O/HIST\%C3\%93RIA\%20DOS\%20M\%C3\%89TODOS\%20DE $\% 20$ ALFABETIZA\%C3\%87\%C3\%830\%20NO\%20BRASIL.pdf>. Acesso em 08/06/2013.

Nobre, I. A. M. et al(2011) "Informática na Educação: um caminho de possibilidades e desafios". Espírito Santo: Gráfica Editora Fátima.

Pressman, R. S. "Engenharia de Software." (1995) São Paulo: Pearson Makron Books.

Ribeiro, Mariana de Souza. "PRO-EDU: Projeto de Apoio Pedagógico aos Alunos em Fase de Alfabetização com o uso do Software Visual Class". Disponível em $<$ http://aberto.univem.edu.br/handle/11077/887>. Acesso em 09/06/2013.

Siqueira, R. N. et al. (2012) "Métodos de ensino adequados para o ensino da geração z uma Visão dos Discentes: um estudo realizado no curso de Graduação em Administração de uma Universidade Federal.". Disponível em < http://xxiiienangrad.enangrad.org.br/anaisenangrad/_resources/media/artigos/epd/19. pdf $>$. Acesso em 13/07/2013.

Stemmer, M. R. G. S. (2001) "O computador e a alfabetização: estudo das concepções subjacentes nos softwares para a educação infantil". Disponível em < www.anped.org.br/reunioes/23/textos/1021T.PDF>. Acesso em 09/06/2013 